\title{
WACANA BIAS GENDER DALAM MASYARAKAT MELAYU DI MALAYSIA: ANALISIS KRITIKAL
}

\section{Rahimin Affandi Abd Rahim, PhD}

Profesor Madya, Jabatan Fiqah dan Usuludin, Akademi Pengajian Islam, Universiti Malaya.Faqir_ila rabbih@um.edu.my

\section{Nor Adina Abdul Kadir}

Calon Bright Sparks Ph.D, Akademi Pengajian Islam, Universiti Malaya.Nor_adina@yahoo.com

\begin{abstract}
This paper illustrates how conventional thinking, liberalfeminism and the reformist's worldview influence the ways in which Muslim intellectuals in Malaysia perceived and responded to the issue of gender bias. Focusing on liberal-feminism, the issue of gender bias in Malaysian society is analysed on the aspects of its ontology, epistemology and axiology. The discussion picks women's role as mother to illustrate the practice of equal treatment of women in Muslim-Malay community.
\end{abstract}

Kata kunci: Bias gender, masyarakat Melayu-Islam, Malaysia

\section{PENGENALAN}

Pada era globalisasi ini terdapat pelbagai tren pemikiran baru yang berkembang pesat di dalam masyarakat. Penyebaran pemikiran bentuk baru yang lebih mudah tersebar melalui pelbagai saluran seperti ICT, internet, penerbitan dan bantuan lebih mudah mempengaruhi masyarakat (Hashim, 2001). Antara isu terbesar yang sering menjadi topik utama dalam media global adalah bias gender ataupun ketidakadilan gender yang diamalkan dalam masyarakat Melayu. Keresahan sosial bagi semua pihak, khususnya penganut Islam dan pihak berkuasa agama akan timbul seandainya isu ini tidak dikaji dengan mendalam. 
Bagi menghadapi perkembangan fahaman dan idealisme baru ini, selain bergantung kepada agensi penguatkuasaan, kita perlu menghadapinya dari segi pemikiran akademik; iaitu menggunakan pendekatan meta-kognitif dengan mengkaji, menganalisis secara kritis, meneliti pola pemikiran, meramal dan mencadangkan jalan penyelesaian masalah yang sepatutnya (Mohd Azhar, 2001). Hal ini menuntut kita untuk meneliti elemen worldview, ontologi, epistemologi dan aksiologi sesuatu fahaman yang dipilih. Pendekatan ini bakal membuat kita terlibat dalam tiga paradigma dan pendekatan kajian ilmu sekaligus. Pertama, aliran tradisional berorientasikan guru yang mengalirkan ajaran secara langsung daripada guru kepada pelajar untuk menjadi insan terbaik sepertimana dikehendaki oleh agama. Kedua, paradigma reformatif yang berorintasi pelajar yang memberi penekanan kepada pelajar untuk melakukan perubahan dan tidak terlibat dengan budaya taqlid semata-mata. Ketiga, pendekatan transformatif yang memberitumpuan kepada sikap kritikal dalam dunia ilmu yang berpotensi untuk membangunkan ilmu baru yang sesuai dengan kehendak agama, kehendak semasa dan amalan sintesis terhadap ilmu sedia ada sehingga mampu melahirkan teori baru berasaskan teori lama. Paradigma yang ketiga ini merupakan tahap tertinggi dalam perkembangan ilmu. Paradigma ini menuntut para cendiakawan Islam menilai secara kritikal semua pandangan ilmu yang dikemukakan oleh para sarjana terdahulu menerusi teori-teori terdahulu; khususnya teori-teori yang dipelopori oleh para sarjana Barat diterjemahkan semula mengikut world-view Islam yang sesuai dengan keperluan tempatan (Syed Muhammad Naquidd Al-Attas, 1979).

Kelemahan utama dunia ilmu Islam di Malaysia adalah kerana kita terikut dengan korpus ilmu yang dibangunkan oleh epistemologi barat. Sudah sampai masanya korpus ilmu barat yang seolah-olah bersifat universal itu dinilai semula oleh sarjana Islam. Dua persoalan berikut, misalnya, boleh menjadi landasan pemikiran untuk kita menilai korpus ilmu barat. Pertama, adakah betul ajaran Islam itu bersifat bias gender ataupun ia ditentukan oleh konstruk ideologi dan sosiologi sesuatu masyarakat? Kedua, adakah betul taklif syarak untuk orang pekak dikecualikan kerana mereka tidak memiliki kemampuan atau alat komunikasi untuk mendapatkan ilmu bagi membolehkan mereka difardukan dengan kewajiban syarak? Teori dan pandangan fuqaha ini tertolak kerana telahpun ada kaedah komunikasi untuk orang pekak yang menyebabkan mereka berpeluang mendapat ilmu seperti mana orang yang normal. 


\section{REALITI WACANA SARJANA ISLAM BERKAITAN DENGAN BIAS GENDER DI MALAYSIA}

Terdapat tiga tipologi tren utama yang membabitkan wacana sarjana Islam berkaitan isu bias gender di Malaysia. Hal ini boleh dikesan berdasarkan kewujudan bentuk-bentuk penulisan yang dihasilkan yang boleh dikelompokkan kepada tiga kategori berikut:

(i) Tradisionalis,

(ii) Feminisme - liberal; dan,

(iii) Reformis-intelektual.

\section{Tren tradisionalis}

Tren tradisionalis menolak dan menafikan sama sekali kewujudan bias gender di dalam sistem fiqhIslam. Tren ini yang rata-ratanya dipegang kuat oleh kalangan ulama tradisional lulusan institusi pendidikan tradisional menganggap idea feminisme adalah pengaruh dari dunia intelektual Barat, diterapkan oleh genre orientalisme Barat yang bertujuan untuk merosakkan dunia umat Islam. Bagi golongan ini, cara dan kaedah terbaik untuk mengatasi isu ini adalah dengan mengamalkan pendekatan backward looking, kembali kepada zaman silam yang lebih murni sifatnya, khususnya dengan berpegang kukuh dan mengekalkan warisan sistem fiqh silam.Dengan paradigma ala-tradisionalis ini, mereka tidak mengemukakan jalan penyelesaian secara mikro terhadap masalah ketidakadilangender yang berlaku. Sebaliknya, mereka mengambil sikap simplistik yang mendakwa jalan penyelesaian masalah dapat dibuat dengan mudah, dengan cara merujuk kepada al-Qur'an dan al-Sunnah serta kitab fiqh klasik, tanpa disertakan dengan blueprint yang lengkap yang lebih sesuai dengan realiti Malaysia moden (Mahmood Zuhdi, 2001).

\section{Tren feminisme-liberal}

Tren feminisme-liberal menerima pakai sepenuhnya pendekatan sekularisme barat dari segi kandungan dan kaedah perjuangan untuk mencapai matlamat. Golongan ini rata-ratanya terdiri dari golongan wanita berkerjaya yang mendapat didikan daripada sistem pendidikan liberal barat dan mendapat pendedahan meluas dari sumber kajian barat, khususnya yang membabitkan isu feminisme. Kemudiannya, dengan pengaruh gerakan kebangkitan semula 
Islam, idea feminisme ala-Women Liberation Barat telah mula mendapat sentuhan daripada idea keislaman dan sekaligus berjaya mengubah tren alasekularisme golongan ini kepada pendekatan dan penghuraian yang lebih bersifat keislaman.Pengaruh aliran ini dalam konteks tempatan umpamanya boleh dilihat daripada kecenderungan yang ditunjukkan oleh Sisters in Islam, iaitu sebuah pertubuhan bukan kerajaan (NGO) yang memperjuangkan isu feminisme dan secara aktif telah menerbitkan pelbagai buku tentang bias gender berperspektif Islam.

\section{Tren reformis-intelektual}

Aliran reformis-intelektual menerima hakikat wujudnya elemen bias gender di dalam Islam. Golongan ini rata-ratanya terdiri daripada lulusan pengajian Islam yang mendapat pendedahan daripada sistem pendidikan Islam di Barat (Azyumardi Azra, 1999; Abdullah Alwi, 1997). Akibatnya, mereka lebih mengamalkan pendekatan yang selektif dan sintesis terhadap kedua-dua tren. Golongan tradisionalis contohnya lebih cenderung untuk menolak sama sekali sebarang usaha reformasi untuk menyelesaikan masalah ketidakadilan gender yang wujud dalam masyarakat. Sebaliknya, feminis sekularisme lebih cenderung untuk menerima pendekatan barat secara mutlak di dalam usaha-usaha reformasi terhadap isu bias gender.

Dalam konteks Malaysia semasa, pandangan ahli aliran feminismeliberal dan reformis-intelektual kelihatan telah banyak mempengaruhi dasar kerajaan yang membabitkan program pembangunan wanita. Contohnya boleh dilihat daripada program reformasi perundangan Islam. Rahimin Affandi (1997) mengambil inisiatif para penggubal dan perancang Enakmen Kekeluargaan Islam Malaysia (EKIM) sebagai contoh bagi menerangkan hal ini. Agak sependapat dengan Horowitz (1994), bersesuaian dengan prinsipprinsip reformisme, perancangan draf EKIM yang baru, seperti Enakmen Kekeluargaan Islam Wilayah Persekutuan perlu mengambilkira beberapa semangat utama yang menunjukkan kedinamikan syariah berhadapan dengan kehidupan moden; iaitu:

1) Keperluan menggunakan sumber rujukan undang-undang Islam yang benar-benar berautoriti merangkumi al-Qur'an dan al-Sunnah berserta dengan ulasan fuqaha Islam yang muktabar.

2) Keperluan untuk mengamalkan sikap yang terbuka di dalam pemilihan pendapat di antara fuqaha Islam tanpa mengira mazhab tertentu (Norhashimah, 1994) dan juga penggunaan metod undang-undang sivil 
moden yang sesuai dengan syarat ianya tidak bertentangan dengan prinsip-prinsip Islam (Abdul Monir, 1992).

3) Keperluan untuk mengurangkan kadar penceraian yang tinggi di Malaysia (Raja Rohana, 1991) yang dilihat antara lainnya sebagai salah satu faktor utama yang menyebabkan timbul permasalahan sosial yang begitu meruncing.

4) Keperluan untuk menjaga kebajikan wanita dan anak-anak daripada sebarang unsur-unsur penindasan dan penderaan (Ahmad, 1986).

Diperingkat institusi pengajian tinggi, yang merupakan medan utama perjuangan reformisme, perdebatan intelektual yang berbentuk cabaran dan pendedahan tentang isu bias gender dari sudut pandangan Islam telah dilakukan secara meluas, sama ada dalam bentuk penulisan ilmiah, kajian terhadap isu lapangan dan ceramah-ceramah akademik.Hal ini secara langsung telah mampu menyedarkan anggota masyarakat kampus yang kemudiannya diharapkan akan mempengaruhi masyarakat awam dengan cara yang lebih berkesan. Pendek kata, mahasiswa institusi pengajian tinggi ini diharapkan agar menjadi intelektual ummah dan pemangkin utama untuk membawa perubahan yang lebih positif dalam keadilan gender dalam masyarakat (Rahimin Affandi dan Idris, 2003).

\section{ANALISA PEMIKIRAN FEMINISM LIBERAL DI MALAYSIA}

Dalam bahagian ini, pemikiran feminisme liberal yang merangkumi isu world-view, ontologi, epistemologi dan aksiologi dianalisa secara terperinci.

\section{World-View}

Golongan feminis liberal berpegang kuat kepada world-view barat yang mempromosi hak asasi manusia sejagat. Golongan ini berpendapat pandangan sejagat ini sesuai diaplikasi kepada semua budaya dan masyarakat dunia. Malangnya, mereka terlepas pandang fahaman sekularisme yang sarat terkandung di dalam world-view barat ini. Atas dasar ini, world-view Arab dan Islam yang cenderung bias kepada budaya patriarki sering dijadikan sasaran utama.

Bertitik tolak kepada asas ini, mereka kemudiannya telah menilai sejarah dan sosiologi Melayu-Islam mengikut kacamata world-view barat. Mereka menyatakan kononnya memang ada penindasan terhadap wanita, walaupun sosiologi kekeluargaan Melayu-Islam berbeza daripada realiti barat dan Timur tengah. Bagi golongan ini, pendekatan pendidikan yang 
meletak anak perempuan di rumah dianggap sebagai satu penindasan. Mereka juga menyatakan amalan budaya patriarki cenderung untuk meminggirkan status wanita kepada insan domestik semata-mata.

Jika dirujuk kepada pandangan world-view Melayu dan perkaitannya dengan pendidikan anak perempuan, ternyata sekali dakwaan yang dikemukakan oleh golongan feminis liberal ini adalah satu kesilapan. Sosiologi pendidikan keluarga Melayu terhadap anak perempuan adalah bertujuan untuk melindungi mereka daripada menjadi mangsa penindasan orang luar. Perkara yang lebih penting adalah sosiologi pendidikan keluarga Melayu lebih mengutamakan ajaran Islam sebagai asas pembentukan akhlak dan emosi anak-anak. Hal ini berlaku akibat daripada pemahaman masyarakat Melayu tentang world-view Islam sejati. Ia kemudiannya turut diterapkan sepenuhnya dalam kehidupan bermasyarakat. Hasil penelitian yang dibuat oleh Hashim (2001) mendapati pembinaan tamadun Melayu ini telah diasaskan dengan enam pandangan world-view yang bersumberkan wahyu Allah. Keenam-enam pandangan ini telah menjadi pegangan utama masyarakat Melayu; khususnya di dalam pembinaan konsep jati diri Melayu, yang terdiri antara lainnya:

1) Alam ini hasil ciptaan dan tabdiran Allah yang mencakupi alam primordial (arwah), alam dunia dan alam akhirat. Alam akhirat adalah destinasi dan natijah muktamad dari kehidupan di alam dunia. Kejayaan hakiki di alam akhirat adalah dapat memasuki syurga dan kejayaan di alam dunia adalah ketaatan kepada Allah.

2) Islam adalah panduan dari Allah sebagai al-Din yang mengandungi segala peraturan bagi segala gelagat hidup di dunia untuk individu dan masyarakat demi untuk kejayaan hakiki mereka.

3) keyakinan kepada pembalasan yang baik bagi amalan yang baik dan sebaliknya pembalasan yang buruk untuk amalan yang buruk.

4) wawasan, misi, objektif, niat, strategi dan operasi segala bidang kerja hendaklah salih, benar dan mematuhi segala aspek hukum Islam tanpa kompromi, manipulasi dan tolak ansur.

5) nilai tertinggi dikaitkan dengan segala perkara yang membantu pembentukan insan yang beriman, beramal salih dan berakhlak mulia yang manafaatnya dapat dinikmati sama oleh orang lain.

6) kehidupan pertengahan dan seimbang antara jasmani, akali dan rohani berasaskan kepada ilmu pengetahuan dalam bentuk fardhu Ain dan fardhu kifayah. 
Merujuk khusus kepada soal sifat dan keunikan emosi manusia, Nur Atiqah (2000) telah menegaskan:

\begin{abstract}
"emosi dapat diibaratkan seperti sungai, samada tenang atau deras dan bergolak. Walau bagaimanapun, arus sungai yang deras boleh dikawal dengan disediakan saluran sehingga dapat digunakan untuk kesejahteraan manusia sejagat. Sebaliknya, sekiranya sungai itu dibiarkan begitu sahaja, ia akan menyebabkan pelbagai bencana dan malapetaka. Seperti juga dengan emosi, seandainya manusia terlalu menuruti dorongan perasaan semata-mata, emosi akan menyebabkan pelbagai kesan negatif. Manusia justeru itu perlu memiliki kemahiran untuk mengendalikan dan mengatur perasaan dan emosi mereka. Manusia harus menjadi tuan terhadap diri sendiri dan bukannya menjadi hamba kepada emosinya."
\end{abstract}

(hal. 289-290)

Dalam masyarakat Melayu, konsep "menjadi orang" merupakan satu elemen akhlak baik yang amat dipentingkan (Kim, 1995). Masyarakat Melayu-Islam mempercayai bahawa manusia berbeza daripada mahkluk lain seperti haiwan dan jin. Bagi manusia Melayu-Islam, makhluk lain seperti haiwan, hantu dan jin merupakan makhluk yang mempunyai kedudukan yang rendah di sisi Allah. Berbeza daripada haiwan, hantu dan jin, manusia terbentuk daripada tiga elemen utama, iaitu roh, jasad dan akal yang perlu dibangunkan secara bersepadu di dalam program pembangunan masyarakat (Rahimin Affandi, 2005). Hal ini bertepatan dengan fakta bahawa agama Islam telah menjadi sumber jati diri dan tenaga penggerak utama ke arah penambahbaikan masyarakat Melayu (Hashim, 2001).

Bertepatan dengan pandangan yang diutarakan oleh Syed Muhammad Naquid al-Attas yang membuat ulasan terhadap kitab Jawi sarjana Melayu-Islam silam, kita boleh menegaskan bahawa konsep menjadi orang ini sebagai usaha melahirkan insan adabi; iaitu manusia beradab yang merupakan neraca tertinggi yang sepatutnya dilahirkan oleh sistem pendidikan Islam. Tugas kerasulan Rasulullah ditumpukan khusus untuk melahirkan manusia yang beradab ini. Dalam soal ini, beliau menegaskan (dalam Wan Mohd Nor, 2006): 
"insani adabi (insan yang beradab) adalah insan yang sedar insaf akan tanggungjawabnya kepada Allah sebagai tuhan yang sebenarnya disembah; yang memahami dan melaksanakan tanggungjawabnya kepada diri sendiri dan kepada masyarakat dengan adil. Dan yang sentiasa berusaha memperbaiki setiap aspek dirinya ke tahap yang lebih sempurna."

(hal. 149-157)

\section{Ontologi}

Secara terang-terangan kita dapat mengesan golongan feminis liberal seperti menafikan wujudnya alam akhirat yang bakal menghukum kesalahan manusia semasa di dunia. Mereka kurang memberi pertimbangan kepada alam akhirat. Lebih mendukacitakan lagi, golongan ini turut sama terlibat dalam aktiviti pluralisme agama yang melampau; iaitu menafikan kebenaran ajaran Islam itu sendiri. Hal ini boleh dilihat daripada usaha golongan ini melancarkan beberapa perkara, antaranya:

Menyokong Tuntutan Suruhanjaya Antara Agama (Inter Faith Comission atau IFC)

Selain memainkan peranan di akhbar, SIS dan JAM juga dilihat menonjol dalam menyokong penubuhan Suruhanjaya Antara Agama (IFC) yang diseminarkan pada 24 Februari 2005 (Anis Shakila, 2006). IFC merupakan suruhanjaya yang ditubuhkan oleh Majlis Peguam Malaysia dan disokong oleh Majlis Perundingan Malaysia bagi Ajaran Buddha, Kristian, Hindu dan Sikh (MCCBCHS) dan Yayasan Konrad Adenauer. Kehadiran Yayasan Konrad Adenauer dalam usaha menubuhkan IFC ini amat diragui kerana yayasan ini beribu pejabat di Jerman dan cuba mencampuri urusan dalaman negara ini. IFC juga mempunyai peranan sebagai penyiasat, perantara, perunding dan pendamai terhadap dakwaan perbuatan yang menjejaskan keharmonian agama.

Pada asalnya IFC ialah Inter Religious Council (IRC), yang merupakan sebuah suruhanjaya yang dicadangkan seperti badan berkanun yang mempunyai kuasa undang-undang yang boleh mengubah ajaran sesetengah agama, akibat daripada desakan penganut agam lain. Badan ini 
berfungsi untuk menerima dan melayan aduan-aduan berkaitan agama. Gagasan penubuhan IFC oleh MCCBCHC (Malaysian Consultative Council of Buddhism,Christianity, Hinduism, dan Sikhism atau Majlis Perundingan Malaysia agama Buddha, Kristian, Hindu dan Sikh) melalui memorandum kepada Majlis Peguam bertarikh 21 Ogos 2001. Matlamat penubuhan IFC adalah untuk meminda beberapa ajaran asas Islam dan berpihak kepada kepentingan penganut agama lain. Tuntutan orang bukan Islam melalui IFC adalah (Anis Shakila, 2006):

1) Seseorang anak yang dilahirkan oleh ibubapa Islam tidak seharusnya secara terus menjadi orang Islam.

2) Orang-orang bukan Islam yang telah memeluk agama Islam hendaklah diberikan kebebasan untuk kembali kepada agama asal mereka (murtad) dan tidak dikenakan tindakan undang-undang.

3) Sebarang kes pertukaran agama Islam kepada bukan Islam tidak sepatutnya dikendalikan oleh mahkamah sivil.

4) Tidak perlu dicatatkan di dalam kad pengenalan seseorang Muslim bahawa ia beragama Islam.

5) Orang-orang bukan Islam tidak perlu dikehendaki menganut agama Islam sekiranya ingin berkahwin dengan orang Islam. Orang Islam hendaklah dibenarkan keluar daripada Islam (murtad) sekiranya ingin berkahwin dengan orang bukan Islam tanpa boleh dikenakan apa-apa tindakan undang-undang.

6) Seseorang pasangan suami atau isteri yang menukar agama dengan memeluk Islam tidak patut diberikan hak jagaan anak.

7) Orang bukan Islam yang mempunyai hubungan kekeluargaan dengan seorang yang memeluk Islam hendaklah diberikan hak menuntut harta pusaka selepas kematiannya.

8) Kerajaan hendaklah menyediakan dana yang mencukupi untuk membina dan menyelenggarakan rumah-rumah ibadat orang bukan Islam sebagaimana kerajaan menyediakan dana untuk masjid.

9) Orang bukan Islam hendaklah dibenarkan dan tidak boleh dihalang daripada menggunakan perkataan-perkataan suci Islam dalam percakapan dan sebagainya.

10) Bible dalam bahasa Malaysia dan bahasa Indonesia sepatutnya dibenarkan edar secara terbuka.

11) Pelajaran agama bukan Islam untuk penganut agama itu hendaklah diajar di semua sekolah.

12) Program-program berunsur Islam dalam bahasa ibunda sesuatu kaum hendaklah ditiadakan. Program dakwah agama lain selain Islam pula 
hendaklah dibenarkan untuk disiarkan dalam bahasa ibunda masingmasing.

13) Orang Islam yang membayar zakat tidak sepatutnya dikecualikan membayar cukai pendapatan dan wang hasil zakat sepatutnya digunakan juga untuk keperluan orang bukan Islam.

14) Sepatutnya Islam tidak disebut sebagai pilihan pertama masyarakat seperti dalam soal pakaian menutup aurat kepada pelajar sekolah.

Tuntutan IFC ini telah mendapat tentangan habis-habisan oleh pelbagai NGO Islam. Malah, pihak kerajaan sendiri menolak cadangan penubuhannya. Penolakan NGO Islam ini membuktikan bahawa masyarakat Islam di Malaysia masih beristiqamah mempertahankan dominasi Islam di dalam masyarakat Malaysia. Pertubuhan yang menolak IFC ini dilaksanakan di Malaysia, ACCIN ( Allied coordinating Committee Of Islamic N.G.O.s) dengan tepat menjangkakan keburukan Suruhanjaya IFC (Mustafa, 2005).

\section{Kempen Anti Kawalan Moral}

Pada awal tahun 2005, SIS bersama dengan NGO bukan Islam telah berusaha memperjuangkan pengembangan budaya hedonisme secara langsung apabila mereka melancarkan kempen anti kawalan moral oleh pihak berkuasa agama dan kerajaan tempatan. Kempen ini dilancarkan ekoran tindakan para penguatkuasa Jabatan Agama Islam Wilayah Persekutuan (JAWI) menahan lebih 100 orang pengunjung kelab malam Zouk di Kuala Lumpur. Mereka ditahan atas pelbagai kesalahan seperti kesalahan meminum arak dan berpakaian kurang sopan. Bagi SIS, tindakan pihak JAWI dianggap bertentangan dengan konsep liberalism barat yang memberi hak kebebasan individu melakukan apa sahaja tindakan yang diinginkannya. Menurut mereka: "bagaimana seseorang itu berpakaian dan di mana, bagaimana dan dengan siapa mereka ingin bergaul adalah terserah kepada pilihan individu itu sendiri."

\section{Kes Kumpulan Artikel 11}

Kumpulan Artikel 11 ditubuhkan pada bulan Mei 2004. Kumpuan ini merupakan gabungan 13 NGO yang memperjuangkan usaha untuk menegakkan keluhuran perlembangaan dan mengalakkan kebebasan beragama di Malaysia. Kumpulan Artikel 11 menolak diskriminasi individu 
atas dasar agama, bangsa, tempat lahir atau jantina. Mereka menggesa agar kebebasan berfikir, beragama dan suara hati setiap individu dihormati, dijamin dan dilindungi. Dalam surat terbuka kepada pihak kerajaan, mereka menyatakan komitmen yang teguh terhadap perlembagaan Malaysia sebagai Negara sekular dan hak kebebasan beragama.

Berdasarkan keputusan Mahkamah Agung dalam Kes Che Omar Lawan Pendakwaraya, kumpulan ini berpendapat bahawa undang-undang Malaysia adalah bersifat sekular. Justeru itu, mereka mengkritik mahkamah sivil yang enggan melayani kes-kes yang mempunyai elemen undangundang Islam berdasarkan peruntukan perkara 121 (1A) Perlembanggan Persekutuan. Mereka seterusnya menggesa kerajaan agar memansuhkan perkara 121 (1A) untuk membolehkan Mahkamah sivil mendengar kes-kes yang sepatutnya berada dalam bidangkuasa Mahkamah Syariah.

\section{Kes Kerajaan Langit Ayah Pin dan Kes Kamariah Ali}

SIS secara lantang membela kebebasan Ayah Pin untuk menganut agamanya sendiri dan menempelak hebat kewibawaan Jawatankuasa Fatwa Negeri Terengganu dan tindakan Jabatan Agama Islam Negeri Terengganu yang mengisytiharkan ajaran kerajaan langit Ayah Pin sebagai sesat dan bertentangan dengan ajaran Islam. SIS dan SUARAM menyifatkan tindakan pihak berkuasa agama ini sebagai penindasan terhadap kelompok agama minoriti dan pencabulan hak kebebasan beragama. SUARAM telah memfailkan aduan kepada PelaporKhas Mengenai Hak Kebebasan Beragama Pertubuhan Bangsa-Bangsa Bersatu dengan mendakwa bahawa pihak kerajaan telah melakukan penindasan terhadap Ayah Pin dan pengikutnya. Hal yang sama dilakukan dalam Kes Kamariah Ali \& Ors Lawan Kerajaan Kelantan \& Anor. Dalam kes ini Daud Mamat, Kamariah Ali, suaminya Mohamad Ya dan Md Yaacob Ismail telah melakukan kesalahan yang secara terang-terangan mengaku telah murtad sebagai cara untuk melepaskan diri daripada hukuman Mahkamah Syariah, sebagai akibat daripada keterlibatan mereka dengan kumpulan ajaran sesat.

\section{Kes Azlina Jailani (Lina Joy)}

SIS dan NGO bukan Islam seperti kumpulan Artikel 11 secara lantang membela tuntutan Azlina Jailani yang telah murtad untuk menukar status agama Islam kepada agama Kristian di dalam Kad Pengenalannya. Walaupun tuntutan ini telah ditolak oleh Pihak Mahkamah Agung di Malaysia, namun SIS dan NGO terbabit masih lagi mengungkit kes ini 
sebagai bertentangan dengan kebebasan individu seperti mana dibawa oleh fahaman liberalism barat.

\section{Epistemologi}

Dalam soal epistemologi ini, kemungkaran yang dipegang oleh golongan feminis liberal amat jelas sekali. Mereka secara langsung berpegang kepada falsafah sains Barat yang bersifat Antroposentrisme (Secular). Pemikiran sains barat dibangunkan berasaskan kepada paradigma logikal empirikal positivisme yang beranggapan ilmu yang sahih hanya boleh dihasilkan menerusi kaedah penyelidikan saintifik yang sistematik, teliti dan bersifat objektif (Mohd. Natsir, 1997). Sebaliknya, pengkajian yang berpandukan sumber wahyu dianggap sebagai tidak saintifik dan tidak boleh dibuktikan secara empirikal yang menyatakan semua perkara yang boleh ditangani secara lahiriah dengan pancaindera (Abdul Rahman, 2000). Pendekatan ini pada dasarnya berpunca dari sikap mereka yang menolak agama dan perkara-perkara ghaib yang tidak dapat dilihat dan ditangani dengan pancaindera (Louay, 1998).

Asas epistemologi ini kemudiannya telah menyebabkan mereka berpegang kepada beberapa butiran lain. Contohnya, menolak dan mencabar warisan tradisi ulamak silam. Berpandukan kerangka epistemologi sekularLiberalisme, golongan ini telah mencabar warisan kitab turath silam. Dalam membuat tafsiran terhadap ajaran Islam, golongan ini telah menggunakan kaedah yang longgar dan bertentangan dengan kaedah sarjana Islam silam. Memandangkan elemen tradisi perlu ditanggap secara negatif, mereka enggan menerima syarat asas pengetahuan Islam yang ditetapkan oleh sarjana Islam silam, seperti (Rahimin Affandi, 2006):

1) Kepentingan mengetahui bahasa Arab untuk mendalami kandungan alQuran dan Sunnah. Bagi golongan ini, pada masa sekarang, pemahaman terhadap ajaran Islam boleh dilakukan oleh sesiapa sahaja yang mampu memahami bahasa Inggeris, khususnya dengan membaca bahan rujukan ajaran Islam yang dihasilkan oleh sarjana Barat.

2) Menolak Hadith Rasulullah sebagai salah satu sumber hukum Islam yang berotoriti bagi memperincikan kandungan Quran. Hadith adalah ciptaan ulamak Islam pada abad ke dua Hijrah yang dinisbahkan kepada Rasulullah sebagai cara untuk mendapatkan keabsahan otoritinya.

3) Imam Shafi'i adalah orang utama yang perlu dipersalahkan kerana beliau merupakan orang pertama yang mengemukakan teori hadith 
sebagai otoriti pegangan selepas al-Quran dan mengasaskan kerangka ilmu usul al-fiqh yang perlu dipakai untuk membangunkan sistem fiqh Islam.

4) Pemimpin umat Islam perlu menjalankan dasar pemerintahan mengikut kesesuaian dengan realiti tempatan tanpa perlu terikat dan mengikut apa yang dijalankan oleh Rasulullah melalui sunahnya.

5) Semua taklif syarak yang difardukan kepada umat Islam tidak didatangkan dan bersumberkan kepada otoriti hadith, tetapi semuanya pada hakikatnya telah diwariskan sejak zaman Nabi Allah Ibrahim lagi.

6) Hadith hanya akan menyebabkan umat Islam menjadi fanatik, mundur dan tidak bersifat intelektual, memandangkan hadith itu sendiri bertentangan dengan al-Quran, sains dan sejarah kemanusiaan.

7) Isu penentangan terhadap fahaman ortodoksi yang kononnya menegaskan bahawa golongan ulamak-pemerintah yang menguasai dan memonopoli pentafsiran Islam yang sejati. Lebih lanjut lagi, gabungan erat antara kedua autoriti ini telah dipergunakan sepenuhnya bagi tujuan pengekalan status quo mereka,sehingga sanggup menindas sesetengah golongan yang cuba mencabar dominasi kuasa ini.

Seterusnya, contoh kedua boleh dilihat menerusi penghinaan mereka terhadap peribadi Rasulullah dan ulamak silam. Masyarakat Melayu-Islam di Malaysia memang cukup sensitif dengan isu kerasulan Rasulullah. Namun sejak akhir ini kita telah dikejutkan dengan wujudnya beberapa golongan yang berstatus sarjana, yang telah memberikan tafsiran yang mengelirukan tentang Islam. Apa yang menyedihkan, terdapat beberapa idea yang mencabar kesucian diri Rasulullah sendiri dan ulamak Islam. Antara pandangan yang boleh dimasukkan dalam bentuk yang menghina Rasulullah adalah:

1) Tindakan yang secara terang-terangan menghina peribadi Rasulullah, yang digambarkan sebagai seorang biasa dan mementingkan hawa nafsu dengan memiliki ramai isteri dan gundik(Farish, 2000).

2) Perjuangan Rasulullah bukannya berbentuk Risalah Kenabian seperti mana termasuk dalam rangkaian kenabian yang terdahulu, tetapi lebih berbentuk perjuangan kemanusiaan seperti tokoh-tokoh yang lain iaitu perjuangan berasaskan Arabisme (tribal leader) yang bertujuan mengangkat martabat bangsa Arab berbanding dengan bangsa bukan Arab (Farish, 2001). Apa yang memalukan lagi, pandangan ini bertentangan sama sekali dengan nisbah keunggulan yang telah diberikan sendiri oleh penulis barat yang begitu menyanjung kehebatan perjuangan Rasulullah (Watt, 1951). 
3) Sifat yang menyama tarafkan antara peribadi Rasulullah dengan tokoh lain, dengan tidak perlu menerima otoriti dan butiran pengajarannya yang terkandung di dalam Sunnah Rasulullah. Sebaliknya, penganut Islam hanya perlu berpegang kepada sumber al-Quran semata-mata (Mohd. Napiah, 1998). Pandangan ini merupakan taktik terpenting orientalis di dalam menolak kesucian Rasulullah dan segala perkara yang dikaitkan dengan Baginda, dengan harapan kemudiannya dapat membuktikan kesalahan ajaran Islam yang terbina di atas keterangan alQuran dan Sunnah Rasulullah (Mohd. Napiah, 1998).

4) Tindakan yang menyebarkan sikap dan pendekatan mungkar ala barat yang menganggap biasa sesuatu pandangan yang menghina diri Rasulullah dan tokoh agama, yang kononnya bersesuaian dengan konsep kebebasan bersuara dan mengeluarkan pendapat yang amat ditekankan oleh pemikiran demokrasi moden. Akibatnya, anggota masyarakat termasuklah penganut Islam akan mengamalkan sikap tidak apa terhadap tindakan yang mengutuk Rasulullah, seperti mana berlaku secara berleluasa dalam masyarakat barat (Wan Mohd Nor, 2000).

Akhirnya, contoh ketiga yang ingin penulis tonjolkan adalah semua sumber ilmu barat dijadikan neraca asas untuk merangka program Hak asasi Wanita. Sumber Islam hanya dijadikan tempelan dan alat justifikasi idealism barat semata. Mereka mengamalkan sikap sinikal melampau terhadap sumber turath Islam, kerana sudahpun ada Pre-Conquive Idea terhadap keburukan sumber turath Islam. Kononnya ia dibuat dengan pengaruh budaya patriarki yang bias kepada wanita.
Aksiologi
Bagi golongan feminis liberal ini, neraca womenhood barat diutamakan. Ia kerap kali bersumberkan budaya hawa nafsu (humanisme-sensate culture). Budaya ini berpandukan sepenuhnya kepada akal dan nafsu manusia semata- mata. Mengikut pandangan faham sekularisme, neraca utama bagi sesuatu kebenaran, etika dan perbuatan yang baik itu bergantung kepada lima prinsip berikut (Rahimin Affandi, 2003):
1) Prinsip vitalisme - apa-apa sahaja yang berbentuk kuat dan menguntungkan dari segi kebendaan akan dianggap sebagai baik. 
2) Prinsip kreativiti - apa-apa sahaja yang boleh mencetuskan daya kreativiti dan menghasilkan ciptaan baru akan dianggap sebagai baik dan bermutu.

3) Prinsip relatif - tidak ada suatupun konsep dan pemahaman terhadap sesuatu fakta ataupun teori yang bersifat mutlak dan kekal. Sebaliknya semuanya boleh berubah mengikut perubahan zaman dan perkembangan ilmu pengetahuan.

4) Prinsip hedonisme - apa-apa sahaja yang boleh memuaskan hawa nafsu manusia akan dianggap sebagai baik, manakala apa-apa sahaja yang boleh membawa penderitaan nafsu akan dianggap sebagai buruk.

5) Prinsip majoriti /plural- apa-apa sahaja yang disukai oleh trend dan kecenderungan sesuatu masyarakat akan dianggap sebagai baik.

Pegangan golongan feminis liberal dengan sistem nilai barat secara terangterangan boleh dirujuk kepada kempen anti kawalan sosial yang mengalakkan golongan muda berhibur melampaui batas dan penolakan mereka terhadap institusi perkahwinan, khususnya bagi seseorang wanita yang ingin berkerjaya dan menceburi bidang kemasyarakatan. Bagi golongan feminis barat, wanita moden perlu meninggalkan institusi perkahwinan yang dianggap telah dicipta oleh budaya patriarki untuk menindas dan memerangkap golongan wanita agar menjadi hamba seks kepada lelaki. Apabila seseorang wanita berkahwin, mereka secara pasti terpaksa terlibat di dalam aktiviti domestik tanpa diberikan apa-apa bayaran. Maknanya selain dari tugas biasa di pejabat, seseorang wanita yang berkahwin terpaksa mengandung, melahirkan dan mendidik anak, di samping terpaksa melakukan tugas-tugas sebagai suri rumah (Zaleha dan Raihanah, 2003). Sebagai gantinya, golongan wanita digalakkan untuk menjadi wanita berkerjaya sepenuh masa demi untuk mobiliti diri sendiri dan patut mengamalkan seks bebas tanpa sebarang ikatan untuk memenuhi keperluan naluri kelamin mereka (Zeenath, 2001).

Walaupun pandangan ini kelihatannya agak keterlaluan jika dilihat dari konteks masyarakat Melayu, tetapi dilihat dari perkembangan semasa, pandangan ini sedikit sebanyak telah diterima oleh sesetengah kalangan wanita di Malaysia (Abdul Rahman, 1997). Untuk berhadapan dengan pandangan ini, kalangan sarjana Islam perlu mampu menonjolkan sifat dinamisme institusi perkahwinan di dalam Islam, yang tidak hanya mementingkan keperluan material semata-mata bahkan turut menekankan kepentingan mewujudkan sebuah keluarga mithali yang mampu melahir dan mendidik zuriat keturunan yang berakhlak mulia. 


\section{KEDUDUKAN DAN IDEALISM WATAK KEIBUAN DALAM MASYARAKAT MELAYU-ISLAM}

Penerangan mengenai kedudukan dan idealisme watak dan peranan keibuan dalam masyarakat Melayu dalam bahagian ini dilakukan bertujuan untuk menunjukkan yang masyarakat Melayu melayan kaum wanita dengan mulia. Masyarakat Melayu sangat mementingkan institusi kekeluargaan yang dibentuk di atas dasar agama Islam. Masyarakat Melayu amat mementingkan beberapa perkara dalam kehidupan mereka. Pertama, masyarakat Melayu menganggap institusi perkahwinan bukan setakat untuk memenuhi keperluaan naluri sex semata-mata, tetapi bagi mendapatkan zuriat (anak) sebanyak mungkin. Anak bagi masyarakat Melayu merupakan harta yang paling bernilai sehingga ia digelar sebagai Cahaya Mata yang dikurniakan Allah. Bagi masyarakat Melayu, anak bukan lah suatu bebanan seperti mana difahami oleh masyarakat barat. Anak dianggap sebagai harapan dan masa depan tempat ahli keluarga seperti ibu bapa bergantung harap di hari kemudian. Masyarakat Melayu tidak mengamalkan pendekatan bias gender di antara anak lelaki dan perempuan. Kalau adapun perbezaan ini, ianya dibuat bersesuaian dengan perwatakan jantina seseorang anak. Anak perempuan yang biasanya bersifat lembut ditugaskan untuk membantu kerja ibu di rumah (domestic work), manakala anak lelaki yang mempunyai sifat kasar dan kuat akan ditugaskan untuk membantu kerja bapa di luar rumah.

Keluarga Melayu menghargai setiap anak mereka, sekalipun anak tersebut cacat. Anak yang cacat dianggap oleh keluarga Melayu sebagai pembawa tuah. Terpenting sekali, setiap ibu bapa Melayu berusaha mendidik dan mengharapkan untuk mendapat anak yang soleh. Cita-cita ini dibuat berasaskan kepada pemahaman ajaran Islam dalam dua perkara utama. Pertama, ianya dianggap bakal menjadi shafaat ataupun mendoakan kesejahteraan ibu bapa apabila kedua-duanya meninggal dunia kelak. Ini bersesuaian dengan ajaran Islam yang menegaskan hanya tiga perkara sahaja yang dapat membantu ibu bapa di alam kubur; iaitu doa anak yang soleh, ilmu yang diajar dan dimanafatkan dan sedekah jariah (seperti tanah yang diwakafkan untuk dibuat masjid). Selain itu, masyarakat Melayu juga percaya yang anak soleh yang menjaga kedua ibu bapanya dijanjikan pahala yang amat besar di sisi Allah. Kedua, pembahagian peranan ibu dan bapa yang seimbang dalam pendidikan anak-anak. Peranan bapa lebih 
dikhususkan untuk mencari rezeki di luar rumah, di samping bertindak sebagai pembentuk disiplin kepada anak-anak.

Berbanding dengan golongan lelaki, kaum wanita telah dianugerahkan tuhan sebagai insan yang terbaik untuk memainkan watak sebagai ibu dengan segala elemen spiritual, emosi, penyayang, bertimbang rasa, lemah lembut, pendidik yang tabah, pemaaf, pendengar yang terbaik, penyejuk jiwa, pemujuk yang baik dan banyak lagi (Azizan, 1985). Semua sifat berkenaan boleh digunakan sebagai mekanisme terbaik untuk proses pembentukan keluarga Islam yang sejati. Peranan ini walaupun dianggap sebagai remeh oleh sesetengah wanita moden, ianya boleh dikatakan benteng, penapis dan harapan terakhir untuk proses pembentukan keluarga mithali; apatah lagi dalam konteks keadaan semasa yang sedang berhadapan dengan krisis sosial remaja semasa yang menyaksikan unsur perosak lebih banyak dibandingkan dengan unsur pendidik (Saedah, 2001).

Sebagai analogi dan rujukan khusus kepada kaum ibu, masyarakat Melayu banyak bergantung kepada kupasan Imam Ghazali. Beliau memperihalkan beberapa perkara utama bagi menyedarkan masyarakat tentang peri pentingnya peranan ibu di mainkan sebaik mungkin.

Antaranya:

(1) fakta sejarah mencatatkan tentang polisi Fir'aun yang membunuh semua bayi lelaki dari kaum Bani Israil kerana dibimbangkan akan mengancam kekuasaannya. Pada masa itu, terdapat dua bayi lelaki Bani Israil yang dilahirkan; Musa Alaihi Salam dan Musa Samiri. Allah telah mengilhamkan kepada kedua-dua ibu bayi tersebut untuk menghanyutkan bayi mereka ke dalam Sungai Nil. Bakul yang mengandungi Nabi Allah Musa telah hanyut dan sampai ke istana Fir'aun, yang kemudiannya dijaga dan dididik oleh Asiah (isteri Fir'aun dan juga seorang ibu). Manakala bakul yang mengandungi Musa Samiri telah sampai ke dalam suatu gua, dan kerana sifat Kasihan Belas Allah, dua malaikat telah dihantar untuk menjaga Musa Samiri. Apa yang berlaku adalah Musa telah berjaya dibentuk dan dididik oleh Asiah dengan watak seorang ibu sejati (dengan hati dan kasih sayang) sehingga kemudiannya menjadi Nabi Allah. Manakala Musa Samiri pula telah menjadi penyesat utama kepada kaum Bani Israil dengan mencipta patung anak lembu daripada emas untuk disembah sebagai tuhan. Maknanya, peranan dan potensi yang dimiliki oleh seorang perempuanibu sejati gagal disaingi oleh malaikat Allah itu sendiri.

(2) setiap tokoh agung Islam yang berjaya dilahirkan dalam sejarah semuanya bermula daripada institusi kekeluargaan yang mengamalkan semangat keislaman sejati. Lebih khusus lagi, mereka dikesan telah 
dididik dan dibesarkan oleh seorang ibu Mithali yang sejati. Hal ini boleh dirujuk kepada data-data peribadi ulama Islam seperti Imam Ali Bin Abi Talib, Hasan dan Husin, Imam Abu Hanifah, Imam Shafi'I, Imam Ghazali, Imam Bukhari, Syeikh Abdul Kadir Jailani dan ramai lagi.

(3) terdapat Hadis Rasulullah yang mafhumnya menerangkan peranan dan susah payah seorang ibu yang mendidik anak-anak agar menjadi seorang muslim sejati sangat besar pahalanya di sisi Allah, bakal dibanggakan oleh Rasulullah (dalam bentuk Syafaat) di Hari Akhirat kelak. Rasulullah juga menerangkan bahawa setiap kata-kata ibu kepada anakanaknya merupakan suatu doa yang tiada hijab (penghalang) untuk sampai kepada Allah secara langsung.

Sekadar untuk mengingatkan tentang peranan ibu di dalam menangani isu krisis sosial remaja Malaysia semasa, penulis memaparkan beberapa fenomena yang berlaku di dalam masyarakat yang secara tidak langsung menggambarkan kerapuhan yang berlaku dalam peranan wanita; khususnya ibu menjalankan peranan sosial mereka.

Muhd. Mansur (2000) mendapati ikatan dan fungsi keluarga Melayu moden sebagai penjaga dan pendidik emosi anak-anak telah mula terhakis. Kerapuhan ikatan dan fungsi ini kemudiannya menyumbang kepada kewujudan pelbagai masalah sosial remaja yang cukup kronik. Kini, golongan remaja Melayu lebih mudah terpengaruh dengan budaya di luar keluarga seperti media massa dan rakan sebaya. Akibat daripada pengaruh media massa, mereka lebih mudah terjerumus dengan hiburan yang mementingkan keseronokan yang melampaui batas, sensasi, glamour dan sindrom kurang daya tahan iman (Nur Atiqah, 2000). Pengaruh rakan sebaya pula menyebabkan mereka terlibat dengan budaya melepak dan pelbagai masalah sosial lain seperti ketagihan dadah, arak, berjudi, menonton video lucah, seks bebas, dijangkiti penyakit AIDS dan banyak lagi masalah lain (Muhd Mansur, 2000). Zakaria (1999) pula mendapati remaja Melayu secara terang-terangan mengaku tanpa segan silu terlibat dalam amalan seks bebas dan menganggap ianya sebagai perkara biasa dan lumrah bersesuaian dengan gaya hidup zaman moden, sepertimana ditonjolkan di dalam media massa moden. Lebih awal daripada kajian Nur Atiqah, Muhd. Mansur dan Zakaria, Rahimin (1994) telah mendapati yangramai daripada kalangan remaja Melayu telah terlibat dengan budaya bohsia dan bohjan. Antara ciri-ciri budaya ini adalah remaja bawah umur yang mengamalkan seks bebas 
sebagai cara untuk mendapatkan keseronokan nafsu semata-mata tanpa rasa bersalah, mengamalkan seks bebas secara "one night stand" dengan sesiapa sahaja tanpa sebarang ikatan cinta dan menganggap gadis yang telah hilang dara sebagai memiliki status yang tinggi di dalam masyarakat moden. Cedukan beberapa dapatan kajian terdahulu memperlihatkan secara terangterangan remaja Melayu telah dilanda krisis sosial yang cukup meruncing. Krisis tersebut membabitkan semua aspek kognitif, afektif dan psikomotor di dalam pembentukan jiwa seseorang remaja Islam. Puncanya, boleh dilihat dari kelemahan pegangan iman, hilangnya pengaruh ibubapa, ketergantungan mereka kepada pengaruh rakan sebaya yang tidak mampu berfikir dengan waras dan terpaksa hidup di dalam suasana masyarakat yang penuh dengan budaya mungkar.

\section{KESIMPULAN}

Sebagai rumusan akhir, dapat dikatakan bahawa apabila proses penganalisaan kritikal dan meta-kognitif dilakukan terhadap fahaman feminisme liberal di Malaysia, ternyata sekali golongan ini memang terpengaruh secara langsung dengan idealism feminisme liberalisme barat. Hal ini boleh dilihat daripada keempat elemen world-view, ontologi, epistemologi dan aksiologi di dalam falsafah yang dipegang oleh gerakan feminis liberal ini. Kita berpendapat bahawa kemungkaran yang dipegang oleh golongan ini perlu ditentang secara wacana ilmiah, selain daripada menggunakan medium badan penguatkuasaan oleh pihak kerajaan sendiri. Sepatutnya, sebarang ruang untuk gerakan ini berkembang perlu ditutup agar ianya tidak mempengaruhi masyarakat awam di Malaysia. Hal ini bersesuaian dengan konsep Sadd Zara'i yang memberi autoriti untuk menutup semua jalan kerosakan yang bakal timbul di dalam masyarakat. Selanjutnya, usaha ini perlu disokong dan diteruskan oleh kalangan sarjana Islam lain sekurang-kurangnya bagi mengelakkan ajaran Islam terus ditohmah dengan pelbagai nisbah yang buruk dan negatif.

\section{RUJUKAN}

Abdul MonirYaacob. (1992). Shariah as A Sources of Malaysian Common Law, SeminarSyariahdan Common Law, Pusat Islam, Kuala Lumpur, pada 16-17hb. Mei 1992.

Abdullah Alwi Haji Hassan. (1997). Penyelidikan Sebagai Asas Kemantapan Pengajian Syariah. Dlm. Mahmood Zuhdi Ab. Majid 
(ed.), Dinamisme Pengajian Syariah, Kuala Lumpur: Berita Publishing, h. 34-35.

Abdul Rahman Abdullah. (1997). Pemikiran Islam di Malaysia: Sejarah dan Aliran. Jakarta: Gema Insani.

Abdul Rahman Abdullah. 2000. Wacana Falsafah Sejarah: Perspektif Barat DanTimur. Kuala Lumpur : Utusan Publication.

Ahmad Ibrahim. (1986). Recent Legislation on Islamic Law in Malaysia. The Law Seminar. IIUM, Petaling Jaya, Julai 1986.

Anis Shakila Ismail. (2006). Pemikiran Islam liberal di Malaysia: kajian terhadap isu yang ditimbulkan oleh Farish Noor dan Syed Akhbar Ali. Kertas projek Sarjana Muda Usuluddin. Akademi Pengajian Islam, Universiti Malaya. Tidakditerbitkan.

Azizan Baharuddin. 1985. Wanita: Hakikat Dan Realiti. Kuala Lumpur : IKD, 1985, H. 33-56.

Azyumardi Azra. (1999). Islam Reformis: Dinamika Intelektual dan Gerakan. Jakarta: LOGOS.

Farish A. Noor. (2000). Let Islam lead the way with its progressive view on sexuality. New Strait Times, 4 November, 2000. . (2001). The Myth surrounding the Islamic state. New Strait Times, 1 Disember 2001.

Hashim Musa. (2001). Merekonstruksi Tamadun Melayu Islam: Ke Arah Pembinaan Sebuah Tamadun Dunia Alaf Baru, Kuala Lumpur: APMUM.

Horowitz, D.L. (1994). The Quran and The Common Law: Reform and The Theory of Legal Change. The American Journal of Comparative Law, v. 42: $570-571$.

Kim Keum Hyun. (1995). Konsep Jadi Orang DalamMasyarakatMelayu: SatuKajianKes Di Negeri Terengganu. Tesis Sarjana Untuk Jabatan Pengajian Melayu, Universiti Malaya. Tidak diterbitkan.

Louay Safi. (1998). Asas-Asas Ilmu Pengetahuan : Satu Kajian Perbandingan Kaedah-Kaedah Penyelidikan Islam Dan Barat, Terj. Nur Hadi Ihsan. Kuala Lumpur: Thinker Library.

Mahmood Zuhdi Ab. Majid. (2001). Bidangkuasa Jenayah Mahkamah Syariah di Malaysia. Kuala Lumpur: Dewan Bahasa dan Pustaka.

Mohd Azhar Abd Hamid. (2001). Pengenalan Pemikiran Kritis Dan Kreatif. Skudai: Penerbit UTM.

Mohd. Napiah Abdullah. (1998). Penolakan hadith oleh orientalis dan penulis Islam. Dalam Islam dalam persepsi orientalisme, Terbitan 
Tak berkala no. 3, Jabatan Usuluddin dan Falsafah, Fakulti Pengajian Islam, UKM, Bangi, hal. 41-44.

Mohd Natsir Mahmud. (1997). Orientalisme: Al-Quran Di Mata Barat (Sebuah Studi Evaluatif). Indonesia: Semarang.

Mustafa Ma. (2005). Ancaman Terhadap Hak-Hak Orang Islam. Persidangan Implikasi Cadangan Penubuhan IFC Terhadap HakHak Orang Islam. Kuala Lumpur.

Muhd Mansur Abdullah. (2000). Renggangnya Hubungan Keluarga Punca Masalah Sosial Remaja, dlm. Mohd. Razali Agus (ed.), Pembangunan dan Dinamika Masyarakat Malaysia, Kuala Lumpur: Utusan Publications, h. 142-151.

Norhashimah Mohd Yasin. (1994). Islamisation or Malaynisation: A Study on The Role of Islamic Law in The Economic Development of Malaysia 1969-1993. Tesis Ph.D, School of Law, University of Warwick. Tidak diterbitkan.

NurAtiqah Tang Abdullah. (2000). Pendidikan Emosi: Kesejahteraan Sosial Pelajar Dan Masyarakat Menjelang Alaf Baru. Dalam Abdul Latif Samian dan Mohamad Sabri Haron (eds.). Prosiding Persidangan Kebangsaan Pengajian Umum Di Alaf Baru. Bangi: Pusat Pengajian Umum, UKM.

Rahimin Affandi Abdul Rahim. (1994). Bohsia: Fenomena Biasa Masyarakat Maju. Majalah Dakwah, bil. 210, November 1994, h. 1114.

(1997). GerakanTajdid di Malaysia: Teori dan Realiti. Dlm. Mahmood Zuhdi Ab. Majid (ed.), Dinamisme Pengajian Syariah. Kuala Lumpur: Berita Publishing, h. 99-101.

(2003). Keistimewaan Islam Sebagai Sistem

Hidup Yang Lengkap. Seminar Keindahan Islam 2003 Peringkat Negeri Sembilan Darul Khusus, Anjuran Bahagian Dakwah, Jabatan Hal Ehwal Agama Islam Negeri Sembilan, di Pusat Dakwah Islamiah Negeri Sembilan, Seremban, pada 25hb.Mac 2003. (2005). Islam Dan Perkembangan Emosi Melayu Selepas Merdeka: Satu Analisis. Dalam Hashim Musa (ed.), EmosiMelayu. Kuala Lumpur: APMUM . (2006). Islam dan Isu Penterjemahan Dalam Era Globalisasi. Dalam Hamidi Mohd Adnan, Penerbitan MalaysiaIndonesia: mengukuhkan Jaringan Penerbitan Nusantara. Kuala Lumpur: Penerbit Universiti Malaya.

Rahimin Affandi Abdul Rahim, \& Idris Awang. (2003). Usaha Memperkasakan Institusi Pendidikan Islam di IPTA Malaysia: Satu 
Analisa Terhadap Pengalaman APIUM. Seminar Kebangsaan Memperkasakan Sistem Pendidikan, anjuran Fakulti Pendidikan UTM, 21hb. Oktober.

Raja Rohana Raja Mamat. (1991). The Role and Status of Malay Women in Malaysia. Kuala Lumpur: Dewan Bahasa dan Pustaka.

Saedah Siraj. (2001). Pendidikan Rumahtangga. Kuala Lumpur: Alam Pintar Enterprise.

Syed Muhammad Naquidd Al-Attas. (1979). Aim and Objective of Islamic Education. Jeddah: University Of King Abdul Aziz.

Lumpur :ISTAC. . (2003). Islam and Secularism. Kuala

Wan Mohd Nor Wan Daud. (2000). Pembangunan di Malaysia. Kuala Lumpur: ISTAC.

Wan MohdNor Wan Daud. (2006). Masyarakat Islam Hadhari: Satu Tinjauan Epistemologi dan Kependidikan Kearah Penyatuan Pemikiran Bangsa. Kuala Lumpur: Dewan Bahasa dan Pustaka.

Watt, W.M. (1951). Clarlyle on Muhammad.The Hibbert Journal, v. xlix, h. 253.

Zakaria Stapa. (1999). AkidahdanAkhlakdalamKehidupan Muslim. Kuala Lumpur: Utusan Publications.

Zaleha Kamaruddin dan RaihanahAbdullah. (2003). Emansipasi Wanita di Abad XXI: Islam Sebagai Model Perjuangan. Multaqa Ulama Sedunia, anjuran YADIM, Putrajaya, 10-12hb. Julai 2003.

Zeenath, K. (2001). Feminist Sexual Politics and Family Deconstruction: An Islamic Perspective. Kuala Lumpur: Universiti Islam Antarabangsa Malaysia. 